\title{
COMPETÊNCIAS E HABILIDADES DO TUTOR EM EAD: DESAFIOS E SUPERAÇÕES
}

José Libório Vilione ${ }^{1}$, Maria Eliza Nigro Jorge ${ }^{2}$

${ }^{1}$ Faculdade de Presidente Venceslau - FAPREV. Professor Especialista, Presidente Venceslau - SP. ${ }^{2}$ Universidade do Oeste Paulista - UNOESTE. Núcleo de Educação a Distância - NEAD, Presidente Prudente - SP. E-mail: vilione@bol.com.br; ilviliione@gmail.com

\section{RESUMO}

O objetivo deste trabalho é realizar uma discussão sobre as competências e habilidades necessárias para um professor/tutor em EaD, seus desafios e superações. Portanto, através de uma pesquisa bibliográfica realizamos levantamentos de alguns pontos imprescindíveis para um bom professor/tutor como: competência e habilidade, funções, papéis, saberes e qualidades. Para tanto, realizamos leituras de livros, artigos, revistas virtuais, dissertações e sites especializados, assim, visando apreender as contribuições de estudiosos do assunto. A pesquisa que realizamos infelizmente não nos indicou uma definição de quais são as competências e habilidades de um professor/tutor, porém, nos deu uma indicação dos caminhos a serem seguidos. Os autores pesquisados nem sempre são convergentes no ideal de competências e habilidades, além de que, esses mesmos autores apontam para outros componentes que fazem parte do perfil de um professor/tutor.

Palavras-chave: EaD. Professor/tutor. Competências e habilidades.

\section{SKILLS AND ABILITIES IN THE TUTOR EAD: CHALLENGES AND overruns}

\section{ABSTRACT}

The objective of this work is a discussion of the skills and abilities necessary for a teacher / tutor in distance education, its challenges and surpassing skills. Therefore, through a literature review conducted surveys of some essential points for a good teacher / tutor as competence and skill, functions, roles, knowledge and abilities. For that, we did book readings, articles, virtual magazines, dissertations and specialized sites, so in order to apprehend the contributions of scholars of the subject. A survey we conducted sadly not tell us a definition of what skills and abilities of a teacher / tutor, however, gave us an indication of the paths to be followed. Several authors are not always converging on the ideal of skills and abilities, in addition to that, these authors point to other components that are part of a teacher / tutor profile.

Keywords: distance education. Teacher / tutor. Skills and abilities. 


\section{INTRODUÇÃO}

Sabemos que a profissão de professor é diferenciada das demais profissões, como afirma Gatti $(1996$, p. 6), pois se trata de uma atividade complexa que tem como foco a formação integral do ser humano, isto é, "[...] na sua intelectualidade, na sua afetividade, nos seus hábitos, para leva-lo à realização de um ideal." (GILES, 1983, p. 27), uma atividade que se torna ainda mais complexa quando se trata da arte de ensinar na modalidade em EaD, pois é "[...] chamado a desempenhar múltiplas funções, para muitas das quais não se sente, e nem foi, preparado" (BELLONI, 2006, p.79), portanto, um questionamento, quem e como vai formar o professor/tutor? Ainda neste sentido a preparação das pessoas em uma sociedade complexa, como a atual, torna o significado da profissão de professor mais ampla, para Perrenoud (1993, p.140), “[...] ser professor hoje em dia significa saber exercer a profissão em condições muito diversas, utilizando uma pedagogia diferenciada, exigindo diferentes níveis de competências para alunos de diferentes capitais escolares".

Complementando essa ideia sabe-se que o professor/tutor da EaD desempenha tarefas que necessitam de competências e habilidades, entre elas: a faculdade de mobilizar e associar um conjunto de recursos ou esquemas mentais de caráter cognitivo, sócio-afetivo e psicomotor (saberes teóricos e da experiência e a afetividade) com a finalidade de solucionar com eficácia uma série de situações novas.

O objetivo deste trabalho é realizar uma discussão sobre as competências e habilidades necessárias para um professor/tutor em EaD, seus desafios e superações. Consequentemente identificar quais as competências e habilidades inerentes a esse profissional.

\section{METODOLOGIA}

Este trabalho foi realizado por meio de pesquisa bibliográfica de cunho científico, que contemplaram uma análise ou investigação, orientada a partir do referencial teórico sobre a temática dos desafios e superações da tutoria em Educação a Distância, suas competências e habilidades como fatores primordiais para desenvolver o bom desempenho do aluno na EaD.

Nesse sentido foi realizado um estudo bibliográfico investigando as características das competências e habilidades técnicas, tecnológicas e pessoais (emocional, afetiva e relação interpessoal) no trabalho tutorial, bem como, as ações planejadas que envolvem a construção de um ambiente responsável e comprometido com a aprendizagem. 


\section{RESULTADOS}

A pesquisa que realizamos através de bibliografias, infelizmente, não nos indicou uma definição de quais são as competências e habilidades de um professor/tutor, porém, nos deu uma indicação dos caminhos a serem seguidos.

Os autores pesquisados nem sempre são convergentes no ideal de competências e habilidades, além de que, esses mesmos autores apontam para outros componentes que fazem parte do perfil de um professor/tutor.

Porém são unânimes em afirmar que para o perfil de um bom profissional da área de educação, seja no modelo presencial ou à distância, é imprescindível a formação e qualificação continuada, ou seja, tal profissional deve estar em constante atualização e adequação para melhor adaptar-se ao momento em que está atuando.

\section{DISCUSSÃO}

Podemos, guardando as devidas proporções, dizer que a origem da modalidade de ensino EaD inicia-se no final do século XVIII (educação por correspondência), com um grande desenvolvimento a partir do século XIX. E no sentido fundamental da sua expressão, é o ensino/aprendizagem que ocorre quando o professor e o aluno separados, temporal e espacialmente, porém, ligados por outro instrumento/ferramenta de comunicação que, podemos chamar de tecnologia. ${ }^{1}$ A segunda geração de EaD com a TV, o rádio, o correio postal e eletrônico (e-mail), a telefonia e as fitas de áudio e vídeo (fita cassete e VHS). Na terceira geração agrega-se os recursos tecnológicos anteriores, mais todos os recursos das TICs e das telecomunicações, introduzindo um novo elemento dando uma nova dinâmica a EaD (LOSSO, 2002).

Porém, para possibilitarmos uma discussão sobre o tema se faz necessário conhecermos a conceituação de EaD, seu breve histórico. ${ }^{2}$ Nesse sentido, Maria Helena Duarte Nunes Pereira busca seu significado em Michael Moore e Greg Kearsley, é o aprendizado planejado para estudantes localizados em lugares diferentes do local do ensino. Exige técnicas instrucionais específicas, de forma a considerar a comunicação mediada por tecnologias e adequadas condições de organização e administração (MOORE; KEARSLEY, 2010, p. 398 apud PEREIRA, 2012, p. 26). Ainda nesse sentido, Nilvania Aparecida Spressola (2010, p.19) diz que "Não há um modelo único

\footnotetext{
${ }^{1} \mathrm{O}$ termo tecnologia aqui, se refere a tudo aquilo que o ser humano inventou, tanto em termos de artefatos como de métodos e técnicas, para estender a sua capacidade física, motora ou mental e sensorial para facilitar e simplificar o seu trabalho.

${ }^{2}$ Para mais: no trabalho de PEREIRA, M.H.D.N. Educação a distância via internet: funções e competências da tutoria. 2012.141 f. Dissertação (Mestrado em Tecnologia) - Centro Estadual de Educação Tecnológica Paula Souza, São Paulo, 2012, p. 34-36, os quadros “2 e 3” trazem sem detalhes.
} 
de educação à distância. Cada instituição de ensino cria seus métodos próprios, utilizando o que tem particularmente de tecnologia".

Portanto, também não podemos definir um modelo único de professor/tutor, bem como definir um modelo único de suas competências e habilidades, pois tais competências e habilidades estão intrinsicamente ligadas ao curso em EaD, que está ligado a uma instituição, sendo que cada curso e cada instituição têm suas particularidades. É claro que não basta uma equipe de tutores capacitados sem a colaboração de uma infraestrutura adequada para a qualidade do curso na modalidade EaD.

Para um curso em EaD, é necessária uma infraestrutura organizacional complexa (técnica, pedagógica e administrativa). O ensino a distância requer a formação de uma equipe que trabalhará para desenvolver cada curso, e definir a natureza do ambiente online em que será criado (ALVES; NOVA, 2003 apud MACHADO; MACHADO, 2004; PEREIRA, 2012, p.50), bem como a organização didático-pedagógica (FILATRO, 2009 apud PEREIRA, 2012, p. 50-51). Aliada a essas especificidades, segundo alguns teóricos, o professor/tutor deve apresentar algumas características como articulador, facilitador e orientador, pois ele é responsável pela mediação pedagógica (LOSSO, 2002; GUTIÉRREZ e PRIETO, 1994, p. 8).

Liliana Dias Machado e Elian de Castro Machado (LITWIN, 2001, p. 99 apud MACHADO; MACHADO, 2004) deixam claro que um bom docente será também um bom tutor. Ainda nesse sentido as autoras sustentam que o saber básico de um docente inclui pelo menos alguns conhecimentos como: conteúdo; pedagógico; curricular; os contextos educacionais; e das finalidades, dos propósitos e dos valores educativos e de suas raízes históricas e filosóficas.

Aliada ao saber básico de um docente, Maria Helena Duarte Nunes Pereira busca afirmar em Oreste Preti que o novo educador precisa formar-se nas técnicas específicas do modelo a distância e que conheça as novas tecnologias para direcionar sua utilização e aplicabilidade em seu trabalho diário junto aos seus alunos (PRETI, 1996, p. 15-56 apud PEREIRA, 2012, p. 32). Nesse sentido, não podemos deixar de reconhecer que, um dos principais desafios do professor/tutor é lidar com as TICS (SOEK; HARACEMIV, 2008, p. 9 apud MANARA; FREITAS, s.d.).

Quanto à competência, pressupõem-se capacidade intelectual e domínio da matéria, destacando-se as técnicas metodológicas e didáticas. Não basta ter competência, esta tem que estar aliada a habilidade (MACHADO; MACHADO, 2004), definida por Eloiza da Silva Gomes de Oliveira, Alessandra Cardoso Soares Dias e Aline Campos da Rocha Ferreira como "um conjunto de conhecimentos, habilidades e atitudes que capacitam um profissional a desempenhar as suas 
tarefas de forma satisfatória" (OLIVEIRA; DIAS; FERREIRA, 2004, p. 22). Tal definição também é compartilhada por Pereira (BELLONI, s.d. apud PEREIRA, 2012, p. 67).

Ainda nesse sentido, Fleury e Fleury (2001) definem competência como um saber agir de forma responsável e reconhecida, que implicará a mobilização, integração, de conhecimentos, recursos e habilidades. Segundo Le Boterf (2003, p. 278) a competência é uma ação ou um conjunto de ações finalizada sobre uma utilidade, sobre uma finalidade que tem um sentido para o profissional.

No entanto, para Perrenoud (1999, p. 90) na área da educação, desenvolver competências significa desenvolver diferentes atributos (conhecimentos, habilidades e atitudes) que combinados podem configurar diferentes formas de realizar com sucesso determinadas atividades vinculadas a uma prática profissional. Ainda para Perrenoud (2000, pág. 15) a definição de competência é a "capacidade de mobilizar diversos recursos cognitivos para enfrentar um tipo de situações".

Ainda nesse sentido, Liliana Dias Machado e Elian de Castro Machado, buscaram a seguinte definição em Carmem Maia: “[...] um professor-tutor, cujo papel é o de promover a interação e o relacionamento dos participantes, uma série de habilidades e competências é a ele necessária" (MAIA, 2002, p. 13 apud MACHADO; MACHADO, 2004), como: Competência tecnológica e

\section{Competências sociais e profissionais.}

Ainda tratando sobre as competências e habilidades, Hugo Assmann (1996, p. 209) acredita quando se fala em caracterização do perfil do professor/tutor é imprescindível que o mesmo tenha habilidade para comunicação, bem como competência interpessoal, liderança, criatividade, capacidade para trabalhar em equipe, comunicação, entre outras.

Nilvania Aparecida Spressola (2010), em sua pesquisa, catalogou 112 competências, porém para torná-las flexíveis à utilização em todas as instituições e agregar competências sinônimas chegou a um número final de 80 competências.

Porém as competências e habilidades de um professor/tutor vão além do que saberes técnicos, Eloiza da Silva Gomes de Oliveira, Alessandra Cardoso Soares Dias e Aline Campos da Rocha Ferreira buscam essa afirmação em Selma Garrido Pimenta que "alerta para a perigosa redução do saberes docentes a competências e da docência a um mero agrupamento de técnicas" (PIMENTA, 2002, p. 47 apud OLIVEIRA; DIAS; FERREIRA, 2004, p. 22). Além das competências e habilidades o professor/tutor necessita possuir algumas qualidades, segundo a definição de $F$. Gutiérrez e D. Pietro, como mencionam Liliana Dias Machado e Elian de Castro Machado (GUTIÉRREZ; PIETRO, 1994 apud MACHADO; MACHADO, 2004): possuir clara concepção de aprendizagem; estabelecer relações empáticas com seus interlocutores; sentir o alternativo; 
partilhar sentimentos; construir uma fonte de instância de personalização, embora à distância; e facilitar a construção do conhecimento.

Durante o desenvolvimento do trabalho, observamos que aliadas à competência e habilidade há várias funções de um professor/tutor, definidas por vários autores, umas convergentes, outras divergentes e outras díspares. Tais como: função pedagógica; função gerencial; função técnica; função social (PALLOFF; PRATT, 2002 apud MACHADO; MACHADO, 2004). Ainda nesse sentido, Maria Helena Duarte Nunes Pereira (2012) descreve as seguintes funções de um professor/tutor, como: funções de ensino; funções de progresso do aluno; funções ao apoio do aluno; funções de retroalimentação (olhos e ouvidos do sistema). Pelo já exposto até o presente podemos observar que os desafios não são poucos.

Além das características mencionadas o professor/tutor deve ter uma identidade que Eloiza da Silva Gomes de Oliveira, Alessandra Cardoso Soares Dias e Aline Campos da Rocha Ferreira buscaram em Antônio Nóvoa os fatores que constroem a identidade do professor,

refere-se aos "Três A" (1991), que alicerçam a construção da identidade docente: adesão (a princípios, valores, projetos coletivos), autonomia (de julgamentos e decisões) e autoconsciência (que permite uma atitude reflexiva sobre a própria ação)".

Conclui que identidade docente "não é um dado adquirido, não é uma propriedade, não é um produto. A identidade é um lugar de lutas e de conflitos, é um espaço de construção de maneiras de ser e de estar na profissão" (NÓVOA, 1991 apud OLIVEIRA; DIAS; FERREIRA, 2004, p. 23).

\section{CONCLUSÃO}

A partir do que foi exposto, observa-se que a função tutorial do professor/tutor em EaD, constitui-se em tarefa bastante complexa, em construção permanente, que envolve aspectos metodológicos, técnicos, teóricos etc. Pressupõe, portanto, que ele possua uma visão clara da construção de conhecimentos como um processo dinâmico e relacional, da metodologia a ser utilizada, dos conteúdos e processos adequados de avaliação e sobretudo, da necessidade de uma atitude de atuação consistente com essa visão.

Verifica-se que apesar da crescente demanda de cursos em EaD, as dúvidas sobre o profissional que conduz este processo de ensino-aprendizagem são muitas. A função de tutor ora se identifica com a de um docente, ora apresenta características de auxílio ao aluno. As atribuições desse sujeito ainda não são tão definidas, acabando por vezes confundindo o estudante, portanto, ainda não podemos definir um perfil do professor/tutor, bem como dar uma identidade para esse profissional da educação. 
É notório que os desafios de um professor/tutor são grandes, mas que a superação desses desafios, em parte, compete principalmente a ele mesmo, através da busca constante de qualificação profissional e pessoal apontadas neste trabalho baseadas nas teorias de vários autores, portanto são vários os caminhos, compete ao professor/tutor escolhe-los e adequá-los as suas necessidades.

\section{REFERÊNCIAS}

ASSMANN, H. Metáforas novas para reencantar a educação. Editora UNIMEP. Piracicaba, SP. 1996.

BELLONI, Maria Luiza. Educação a Distância. 4. ed. São Paulo: Autores associados, 2006.

FLEURY, M. T. L; FLEURY, A. Construindo o conceito de competência. Revista de Administração Contemporânea (ISSN 1415-6555), Edição especial, p.183-196, 2001. Disponível em: http://www.scielo.br/scielo.php?script=sci_arttext\&pid=S141565552001000500010\&lng=pt\&nrm=iso\&tlng=pt. Acesso em 02 janeiro 2014.

GATTI, B. Formação de professores e carreira: problemas e movimentos de renovação. 2. ed. rev. e ampl. São Paulo: Autores Associados, 1997.

GILES, Thomas Ransom. Filosofia da educação. São Paulo: EPU, 1983.

GUTIÉRREZ, F. \& PIETRO, D. A Mediação Pedagógica: Educação a Distância Alternativa. Campinas: Papirus, 1994.

LE BOTERF, G. Desenvolvendo a competência dos profissionais. 3. ed. Tradução Patrícia Chittoni Ramos Reuillard. Porto Alegre: Bookam, 2003.

LOSSO, Adriana Regina Sanceverino. Reflexões sobre a Educação a Distância: o papel do professor tutor na perspectiva da mediação pedagógica. In: Revista UDESC, v. 3, n. 2, 2002. Disponível em: http://revistas.udesc.br/index.php/linhas/article/viewFile/1193/1008. Acesso em 10 janeiro 2014.

MACHADO, Liliana Dias; MACHADO, Elian de Castro. 0 papel da tutoria em ambientes de EaD. Disponível em: http://www.abed.org.br/congresso2004/. Acesso: 27 dezembro 2013.

MANARA, Alecia Saldanha; FREITAS, Indiara. $\mathbf{O}$ trabalho docente do professor tutor na educação à distância. Disponível em: http://www.unisc.br/portal/upload/com_arquivo/o_trabalho_docente_do_professor_tutor_na_e ducaacaao_aa_distaancia. Acesso em 10 janeiro 2014.

OLIVEIRA, Eloiza da Silva Gomes de; DIAS, Alessandra Cardoso Soares; FERREIRA, Aline Campos da Rocha. A importância da ação tutorial na educação a distância: discussão das competências necessárias ao tutor. VII Congresso Iberoamericano de Informática Educativa. Disponível em: http://www.niee.ufrgs.br/eventos/RIBIE/2004/comunicacao/com20-28. Acesso em 10 janeiro 2014. 
PEREIRA, M.H.D.N. Educação a distância via internet: funções e competências da tutoria. 2012. 141 f. Dissertação (Mestrado em Tecnologia) - Centro Estadual de Educação Tecnológica Paula Souza, São Paulo, 2012. Disponível em: http://www.centropaulasouza.sp.gov.br/posgraduacao/trabalhos-academicos/dissertacoes/formacao-tecnologica/2012/maria-helenaduarte.pdf. Acesso em 14 jan. 2014.

PERRENOUD, Philippe. Práticas Pedagógicas, Profissão Docente e Formação: Perspectivas Sociológicas. Lisboa: Publicações Dom Quixote, 1993.

PERRENOUD, Philippe. Construir as competências desde a escola. Porto Alegre: Artmed, 1999.

PERRENOUD, Philippe. Dez novas competências para Ensinar. Porto Alegre: Artes Médicas, 2000.

SPRESSOLA, Nilvania Aparecida. Instrumento para avaliar as competências no trabalho de tutoria na modalidade EaD. Dissertação apresentada ao Departamento de Engenharia de Produção da Escola de Engenharia de São Carlos da Universidade de São Paulo como requisito para a obtenção do título de Mestre em Engenharia de Produção, 2010. Disponível em: www.teses.usp.br/teses/.../NilvaniaAparecidaSpressoladefinitiva.pdf. Acesso em: 16 jan. 2014. 